\title{
Safety practices in the Chemistry Laboratories of higher secondary schools of Samtse District: A case Study in Bhutan
}

\author{
Aita Raj Limboo ${ }^{1}$, Phurba Sonam Waiba ${ }^{2}$, Nandu Giri ${ }^{3}$, Sonam Rinchen ${ }^{4}$
}

${ }^{1}$ Ministry of Education, Royal Government of Bhutan, Bhutan

${ }^{2}$ Ministry of Labour and Human Resources, Royal Government of Bhutan, Thimphu, Bhutan

${ }^{3,4}$ Samtse College of Education, Royal University of Bhutan, Samtse, Bhutan

Received: 01 Dec 2020; Received in revised form: 09 Jan 2021; Accepted: 22 Jan 2021; Available online: 04 Feb 2021 C2021 The Author(s). Published by The Shillonga Publication. This is an open access article under the CC BY license (https://creativecommons.org/licenses/by/4.0/).

\begin{abstract}
Teaching and learning of chemistry involves scientific tests and experiments that take place in laboratories. It involves using hazardous chemicals and equipment posing risks and health hazards to the users. Hence, the users should be thoroughly versed with laboratory safety practices. Therefore, an attempt to understand the safety practices in chemistry laboratories in schools have been examined in this study.

The data were collected administering a mixed method. Both descriptive and inferential statistical tools were used to analyse quantitative data while qualitative data were analysed thematically. Congruency of the eight predetermined themes was established by triangulating the quantitative and qualitative data using Statistical Package for Social Sciences version 21.

The results indicated that the schools had good safety practices with adequate laboratory facilities and safety skills. The schools were also aware of emergency planning and chemical storage and labeling. However, schools lacked properly trained safety practitioners. It was also observed that chemicals and waste materials were disposed of without treatment. Further, it was also observed that there were shortages of safety gloves and goggles fume hood and pipette fillers.

The study recommends school administrators, chemistry teachers, and laboratory assistants to procure unavailable items required for the safe conduct of chemistry laboratory activities. The study further recommends the Ministry of Education (MoE) to provide training to chemistry teachers and laboratory assistants on the safe handling of hazardous materials and on first aid techniques to address accidents.
\end{abstract}

Keywords - Chemistry Laboratory, Safety Practices, Samtse Bhutan.

\section{INTRODUCTION}

The laboratory work is considered very important to promote students' learning of science and scientific inquiry. The teaching of chemistry through laboratory work can help increase students' interest in chemistry. In Bhutan, the science curriculum has given due importance to laboratory works in teaching chemistry. However, there are many hazardous chemicals and equipment in the chemistry laboratories in schools. The chemicals and equipment possess a significant risk of accidents, a threat to human health, and the natural environment. The situation literally demands conscientious care in order to protect human health, conserve the natural environment and to prevent laboratory accidents. Measures to prevent accidents, conserve the natural environment, and protect human health include safety training and enforcement of safety guidelines, use of PPE (PPE), and disposal of the hazardous chemical waste properly. Therefore, it was a sign of exigency to understand the current state of laboratory safety in the chemistry laboratories of higher secondary schools.

\subsection{Background}

The schools must foster a healthy, safe, and supportive learning environment such as conducive physical and psychological ambiance in order to achieve quality 
education [21]. This holistic approach in learning will develop healthy, skilled and productive members of society in the future. According to Bhutan Education Blueprint 2014-2024 [21], the schools have to ensure that children and school personnel are protected from risks and injuries. Moreover, one of the components of the healthy school environment is to prevent children from chemical threats such as air pollution, water pollution, and hazardous waste.

If there is lack of safety, it may result in accidents where students and teachers are exposed to hazardous chemicals and equipment [32]. For instance, the University of California at Los Angeles quickly transformed its laboratory safety program after the incident of a chemical accident in December 2008 that took the life of a student researcher [11]. Likewise, [17] concluded that academic laboratories are unsafe places for work after analysing 94 laboratory incidents identified by Chemical Safety and Hazard Investigation Board (CSB) and other incidents published in the media. The number of accidents and the state of safety practices in the chemistry laboratories of schools in Bhutan is still unknown due to very limited research in this area. The only study by [36] investigated laboratory safety in one of the middle secondary schools in western Bhutan based on students' ability to recognize common hazard symbols. The study stated that the students could hardly recognize the common laboratory hazard symbols. It is then apparent that there should be more research on laboratory safety practices in schools of Bhutan.

In Nepal, a study concluded that there was improper disposal of chemical waste and the lack of monitoring the laboratory safety [16]. Likewise, Li [as cited[14]] stated that the liquid waste from all levels of school laboratories in Taiwan was around 1,691,100 liters in the year 2000 consisting of harmful wastes such as heavy metal liquid, organic liquid, acid and alkaline liquid waste. If appropriate control measures are not taken, such liquid waste can severely impact the environment and affect human health [14]. In Bhutan, protecting our pristine environment from such damaging materials and the welfare of human health cannot be compromised at any cost. Therefore, the proper safety measures and safe work practices in the chemistry laboratories are to minimize the risk of accidents, impact on the environment and human health. Among many, the adoption of safety rules in the laboratories is one of the ways to prevent accidents [31]. However, these skills and knowledge alone cannot assure laboratory safety.

Facilities such as proper ventilation, availability of water, PPE, fume hood, pipette filler, and first aids boxes are necessary. Supposedly, the absence of fume hood, ventilation, and pipette filler will expose students to hazardous chemicals affecting their health over a long period. Inhaling of substances such as acids, ammonia and sulphur dioxide may directly injure the pulmonary epithelium at various levels of the respiratory tract, leading to a wide range of disorders from tracheitis and bronchiolitis to pulmonary edema [12]. Therefore, understanding the current state of safety practices in the chemistry laboratory is timely to make recommendations to prevent accidents, health risk, and protect our environment. The chemistry laboratories are highly unsafe to work due to the use of hazardous chemicals. It makes human health vulnerable and prone to the occurrence of chemical accidents. Therefore, safe practices and necessary precautions are prerequisites.

\subsection{Statement of the Problem}

The study of chemistry beginning from class IX has been one of the impeccable practices in the Bhutanese education curriculum. Further, understanding chemistry through laboratory work is more effective. The education system encouraged inquiry-based learning (learning through practical work) by building infrastructure, recruiting laboratory assistants, and furnishing the laboratories with equipment and chemicals. At present, there are 103 schools with chemistry laboratory facilities in Bhutan, out of which 48 are in higher secondary schools [22]. Moreover, in classes IX-XII, a minimum of 15 chemistry practical works are instituted as a part of the curriculum and assessed as an important component of Continuous Assessment (CA) for classes IX-XI. Bhutan Council for Examination and Assessment assesses the practical works for class XII externally [30]. Hence, the use of chemistry laboratories in schools is extensive and safety is a major concern.

The practical work in teaching and learning chemistry is recommended as it helps students to acquire hands-on skills, develop their understanding of chemistry and to apply in practical life. However, conducting practical work in the chemistry laboratory is a major concern in schools due to lack of proper safety practices. Chemicals such as acids, alkalis, carcinogens, and heavy metals have been another concern due to their harmful effect on human health and the environment. Still, the use of such chemicals is unavoidable and accidents are unpredictable. Therefore, it is imperative to take the necessary precautions to minimize risks and hazards. The studies in other countries found deficiencies in safety practices, safety facilities, and proper hazardous waste management in chemistry laboratories ([2]; [16];[23]. However, there is only one study carried out in Bhutan to investigate laboratory safety limited to students' ability to recognize the common hazardous symbols. The study revealed that 
most of the middle secondary school students in one of the schools of western Bhutan were unable to distinguish the common laboratory hazard symbols. This means students were either complacent to learn or vulnerably unaware of the potential chemical hazards that might cause risk to their lives [36]. Such research carried out to update and find out the ways to improve safety measures to support the practical approach of chemistry education at school level inspired the researcher to explore more. The findings of this study conducted intend to inform and support the REC, MoE, National Environment Commission (NEC), policymakers, government, and educators to ensure and improve safety in the school chemistry laboratories. It is savouring to have adequate safety equipment and other laboratory facilities. Apart from this, well-trained laboratory assistants and teachers to operate safety equipment adequately remain an ideal objective to ensure the safety of the students in the chemistry laboratories. It literally means that the chemistry laboratories in schools should be furnished with adequate safe facilities with competent laboratory assistants and chemistry teachers to facilitate practical works safely.

The safety of the students and teachers is important while handling chemicals and equipment. Numerous literature claims that safety practices in academic chemistry laboratories are lacking. However, those findings were confined to a context other than Bhutan. Since safety practices in the chemistry laboratories of other countries cannot be generalized to Bhutanese context, the mixed method study was carried out to study the current state of safety practices in the chemistry laboratories of higher secondary schools of Samtse Dzongkhag. Under the topic, the study endeavored to find out the current state of safety practices based on the theme; PPE, safety facilities and equipment, general safety practice (GSP), safety knowledge and skills, Hazardous Waste Management (HWM), Emergency Planning (EP), chemical storage and labeling, and finally training and policy.

\subsection{Significance of the Study}

The finding of the research carried out for the current state of safety practices in the chemistry laboratories of higher secondary schools is a preliminary study in Bhutan that adds new knowledge. It can also be the baseline data for future researchers.

The study also aims to support the schools, REC, and educators to plan and improve safety practices in the chemistry laboratories.

As of now, hazardous chemical waste from the chemistry laboratories is disposed of without any treatment. However, time will come when it shows impact. Therefore, before getting late, the findings on the hazardous waste management practices will be a timely eye-opener to NEC, government and other responsible stakeholders. It will not only reduce human health hazards but also save our pristine environment.

It will also help to train and create awareness on laboratory safety practices to the chemistry teachers, laboratory assistants, and students.

\section{LITERATURE REVIEW}

In schools, the chemistry laboratories are susceptible to accidents and safety measures are highly recommended. It is always important to create a culture of safety in the science classroom from the first meeting of the class [4]. However, [16] stated that safety is often neglected in developing countries like Nepal. Further, [19] also stated that laboratories in the academic setting are hardly inspected due to limited professional and laboratory resources [19]. University laboratories are assumed to be a safe place due to the small amount of chemicals used. Therefore, due to less attention, they possess potential risks ([2]. "The National Safety Council has estimated that 5000 safety-related accidents occur in American schools each year; at least ten percent of these are science classroom related" [Stroud as cited in [9], p.149]. Likewise, the study in Nepal indicated 47 percent of the respondents in their study had experienced accidents in the laboratories, mostly due to improper use of acid leading to damaging skin and cloth [16].

According to [16], to reduce the risks of accidents and injuries, the Chemical Hygiene Plan (CHP) should be followed while working in the laboratory. Similarly, [4] guidelines state that every school must have CHP to help protect people while working in laboratories. Similarly, [1] stated that the development of departmental CHP is compulsory to protect laboratory workers from chemical exposure. A proper CHP comprises numerous safety measures such as proper storage of chemicals, safe and proper operation of chemicals and equipment, proper design of experiments and appropriate chemical waste management system [16]. Likewise, [31] suggested preventing laboratory accidents by creating safety awareness in students and making them behave safely.

\subsection{Requirement of Safety Measures in Chemistry Laboratory}

The primary objective of establishing a science laboratory in school is to transform theoretical information into the concrete hands-on experience [36]. [15] stated that practical work has a significant effect on students' achievement. In contrast, findings by [3] showed that laboratory anxiety can happen during the use of chemicals 
and working with laboratory equipment which can lead to accidents or affect students' performances. Therefore, safety practices in the chemistry laboratories are not only to safeguard an individual from the risk of accidents and health hazards but also to ensure effective teaching and learning.

According to [5], the chemicals used in the chemistry laboratories may have health and environmental dangers due to properties such as combustible, flammable, caustic, and toxic. However, Warhurts (as cited in [6] states it is wrong to conclude that chemicals in the laboratory are all hazardous; they too have benefits if they are properly used. However, the findings in Ibadan, Nigeria indicated that the science students were aware of the hazards and the laboratory safety practices but their knowledge was not translated to safe practices. Similarly, a study carried out by [32] reported that the key challenge in the laboratory work is the students' safety behaviour because students taste chemicals, use chemicals more than instructed, and they intentionally expose themselves to each other. Therefore, safety measures are vital in the chemistry laboratory.

\subsection{Personal Protective Equipment (PPE)}

PPE has been considered very important in various working environments for protection. In the chemistry laboratories, the students and teachers must wear an appropriate PPE and clothing. The basic PPE requirement that needs to be equipped while working in laboratories is safety goggles, laboratory coats, and hand gloves. It must be worn all the time when working in the laboratory ([8]; [31]. A study carried out in Nepal found only 57 percent of the participants used gloves while handling chemicals [16], 2017). Similarly, the investigative study in Saudi University found that the number of hand gloves in the laboratory were below average [2]. According to [31], the protective safety goggles must be worn in all circumstances - while heating chemicals, handling corrosives such as acids, alkalis, formalin, and chloroform. Failure to do so shall be regarded as negligence. In contrast, a case study in Pahang, Malaysia found that schools were not preparing enough safety goggles for students when conducting experiments in the laboratories [18]. That being said, there are ways to improve the use of PPE. For instance, unannounced PPE inspections helped to vigorously improve the use of PPE within one year in the University of California at Los Angeles [11].

\subsection{Laboratory Facilities and Equipment}

The facilities in the chemistry laboratory such as water, soap, glass disposal box and safety manual have been basic requirements. [24] stated that the hand washing with soap must be followed immediately after the laboratory work.
Besides hand washing, disposal bins for chemicals residue are one of the most important laboratory requirements. The study conducted in West Virginia high schools found only 66 percent of the science laboratories have some form of glass disposal boxes available [29]. However, guidelines in [31] and [8] states that separate disposal bins, particularly for broken glasses, must be used. The provisions for the ventilation system of the chemistry laboratory include windows, exhaust fans, and fume hoods. According to [13], any discernible chemical smell felt in the chemistry laboratory is an indication of the substance in the gaseous phase and not safe to breathe. The fume hood is an integral part of chemistry laboratory ventilation as the primary safety measure, which prevents laboratory workers from exposure to harmful and hazardous fumes and vapour [1]. The fume hood protects us from exposure and keeps chemical aerosols, vapours, fumes, particulates, and odours under control. However, the study in junior secondary school laboratories in Gaborone has shown that 80 percent of the fume-hoods were non-functional [23]. Similarly, a study carried out in Nepal found only 26 percent of the high school laboratories were possessing fume hood [16]. Therefore, the above studies indicated the lack of fume hoods in the chemistry laboratories. Another, safe equipment to pipette out chemicals is to use aspirator or pipette filler but mouth pipetting should be avoided [8]; [24]; [31]). Further studies to investigate the availability and the use of above mentioned safety facilities and equipment in the school chemistry laboratories is necessary.

\subsection{General Safety Practices (GSP)}

The basic safety practices are equally important to protect oneself from the hazards in the chemistry laboratories. [4] guidelines suggested creating a culture of safety from the first meeting of the class by setting and explaining the appropriate safety rules of the laboratory to the students. The study conducted in Swedish middle and high school reported that all the teachers check the safety knowledge of the students before starting the practical work [32]. While, the findings in Pahang, Malaysia found that only 55.9 percent of the teachers had explained science laboratory safety rules in the beginning of the school session [18].

The four principles of safety by [13] is RAMP (Recognize, Assess, Minimize, and Prepare). The American Chemical Society developed guidelines for chemical laboratory safety for secondary schools using RAMP principle [4]. Under the RAMP concept, in order to minimize risk during the experiment, a teacher should supervise the students closely and carefully in the chemistry laboratory all the time. In agreement to RAMP principle, the study in junior 
secondary school laboratories in Gaborone revealed that practical classes were well supervised by the teachers [23].

There is also other important housekeeping to be followed in the chemistry laboratories. Students should not be allowed to eat or drink anything inside the chemistry laboratory ([4]; [8]; [31]. Another important practice is to ensure that benches must be cleaned before and after the laboratory works ([8]; [31]). According to [4], while handling chemicals and equipment, the long hair should be tied properly. Similarly, [31] states that long hairs are the main cause of fire accidents.

\subsection{Safety Knowledge and Skills}

The students, teachers, and laboratory assistants must have basic safety skills and knowledge, which will ensure to avoid accidents and injuries in the chemistry laboratories. Some of the basic safety skills and knowledge such as, when heating substances, the mouth of the test tube should be pointed away from friends or self ([4]; [8]; [31]) and when acid and water are mixed, acid should always be added to water [31]. Devoid of such basic knowledge and skills will result in accidents and inhalation of chemicals that affect human health. In the chemistry laboratories, working fire extinguishers should be in place and there must be competent personnel to operate during fire disasters. [4] states, "teachers who are authorized to use a fire extinguisher must be trained on its proper use".

According to [8], safety symbols are informative and must be displayed on walls and doors. Similarly, [31] recommended that safety signs are very informative to reduce laboratory accidents. Further, $\mathrm{Su}$ and $\mathrm{Hsu}$ [as cited in [6]] suggested that the accidents related to chemicals mostly occur due to lack of the precautionary symbols on the chemicals. Therefore, it should be mandatory for the students to know common laboratory hazard signs and symbols given in their practical manual. However, the study by [6] indicated that the majority of Thai undergraduate students misunderstood the meaning of safety signs.

\subsection{Emergency Planning (EP)}

The cases of emergencies in the chemistry laboratories are unpredictable and the schools should have an emergency action plan to combat in a safer approach. The study conducted in Saudi University concluded that the schools had unsatisfactory emergency planning and lacked emergency equipment such as showers, eyewash, and fire detector except fire extinguisher [1]. A similar survey conducted in 120 public high schools within Virginia indicated lack of safety showers and chemical spill kits [29]. In contrast, the study in Ten Swedish Schools indicated the availability of regularly checked safety equipment such as safety showers, emergency first aid kit, and eyewash [32]. According to [31], the first aid should be always there in the laboratories in case of an emergency to make the patient feel secure, comfortable and to prevent deterioration of the patient's condition. Therefore, the chemistry laboratories must be well equipped with first aid kits, fire blankets, wash bottles with clean water, fire extinguisher, the evacuation routes, exit signs displayed on the exit doors, and emergency exits doors.

\subsection{Chemical Storage and Labelling}

Lack of proper knowledge about the labeling of chemicals will lead to an accident. Chemical labeling is very important in identifying the nature of the chemical and storing incompatible chemicals separately. These incompatible chemicals should be kept separate during transport, storage, use, and disposal; the incompatible chemicals explode or become highly toxic if they come in contact to each other [24].The proper storage of chemicals in the laboratory can reduce incompatibilities and occupational exposure to chemicals [1]. According to [16], the laboratories must have separate stock rooms for storage of chemicals whereby chemicals are arranged separately according to their hazard category and compatibility. Foster (as cited in Abbas, 2016) also stated that improper chemical storage could increase the risk of laboratory accidents and create a fire hazard, toxic fumes, and an explosion in case of a chemical spill. The survey conducted in Saudi university found poor chemical storage and chemical labeling in terms of segregation of chemicals according to their hazard class [1]. Another study conducted among Thai undergraduate students revealed that the students did not pay attention to safety signs labeled on containers during experiments [6].However, the study in Swedish schools indicated that most teachers were satisfied with the chemical storage facilities [32].

\subsection{Hazardous Waste Management (HWM)}

The hazardous chemical waste is generally categorized into chemical waste that results from laboratory experiments and the expired chemicals. Waste which is hazardous for both people and the environment need to be disposed of safely and correctly [18]. In the United States of America, the U.S. Environmental Protection Agency (EPA) regulates the disposal of toxic waste. Offenders were charged and imposed with severe penalties for violating the waste disposal act that came into force in 1976 [25].

At the University of Tokyo, the Environmental Science Center (ESC) centrally controls hazardous chemicals. The disposals of chemically hazardous waste are as follows: Separation and storage according to a separation reference chart by a waste generator at the experimental site; collection, inspection, and preparation for outsourcing by 
ESC, followed by intermediate treatment and final disposal by an external contractor [35]. In Bhutan, Waste Prevention and Management Act of Bhutan-2009 emphasizes to ensure that hazardous waste is disposed of in an environmentally sound manner to protect and sustain human health through the protection of the environment [28]. Further, a person guilty of an offense shall be liable to be sentenced in accordance with the Penal Code of Bhutan.

According to [16], it is a worldwide general practice to neutralize acid and base before draining into the sink. However, their study found 68 percent of the chemistry laboratories drain acid or base waste without neutralization. Similarly, the study in Saudi University revealed 91 percent of the participants agreed that the liquid chemical waste is disposed of in the sink [2]. However, [31] guidelines advise to segregate the waste appropriately and dispose of them safely, especially waste of heavy metals and acid-based substances. The waste from the school chemistry laboratory directly goes to the open space from the basin. That waste contains heavy metals, acids, alkaline, and organic solvents. The salts of heavy metals used in chemistry laboratories can be lead acetate, copper sulphate, ferrous sulphate, zinc sulphate, barium nitrate, and manganese dioxide [31]. There is an increasing ecological and global public health concern associated with environmental contamination by heavy metals [34]. Chemicals such as Arsenic, Mercury, Lead, and Cadmium have known human carcinogens, these heavy metals, and their compounds can affect human health [20]. In general, humans are more likely to be exposed to metal contamination from soil that sticks to plants than from bioaccumulation [20]. Therefore, heavy metals and related toxic compounds can be hazardous for human health. The heavy metals like iron and copper are required in trace amounts for various metabolic functions but excessive levels can be ecologically unhealthy. The Presence of heavy metals in air, soil, and water can cause bioaccumulation affecting the entire ecosystem and pose harmful health consequences to all life forms [33].

\subsection{Policy and Training}

The policy for laboratory safety practice in schools is for the safety of the students and teachers. If policies and guidelines are missing or not implemented, the safety practices in the chemistry laboratory may be taken for granted and undesirable accidents might occur. The students might be exposed to a chemical that harms their health over a long period. The effect is incommunicable immediately. In a study carried out in Nepal, it was found that 87 percent of the teacher respondents believed there was no government agency to monitor safety issues in the teaching laboratory but the government of Nepal has had safety codes since 1989 [16].

The training on chemical storage and handling are crucial to empower laboratory staff to prevent potential accidents and to prepare them to respond in case of chemical accidents [1]. The teachers must receive all necessary training in case of an emergency because in some cases the teacher may have to act before medical personnel arrives [4]. However, the study in the University of Saudi Arabia found a lack of safety training for laboratory staff [2]. Likewise, the study carried by [23] indicated that 61 percent of the laboratory staff did not receive any training on chemical safety. The policies and training to the teachers and laboratory assistants are very important for the overall safety in the laboratory and cannot be neglected.

\subsection{Concluding Statement}

Teaching chemistry through practical work is found to be very effective. On the other hand, the use of hazardous chemicals and equipment is unavoidable and they pose a threat to human health and environment in the absence of proper safety practices. Therefore, safety practices in the chemistry laboratories are imperative to avoid accidents, reduce human health hazards, and to protect our pristine environment. Literature pointed out that the implementation of CHP, RAMP principles and proper safety guidelines are some of the recommended safety practices. The researcher found eight major themes to be investigated to understand the overall current safety practices in the chemistry laboratories. The eight major themes that were deduced from the literature are PPE, safety facilities and equipment, safety practices, safety knowledge and skills, EP, HWM, chemical storage and labeling, and training and policy. The number of previous study findings in Nepal, Virginia, Saudi Arabia, and Gaborone has indicated a lack of proper disposal of waste, safety facilities, and lack of training for laboratory staff. At the same time, their findings have also shown adequate safety practices in some of the areas. However, these findings in other countries cannot be generalized to the Bhutanese context. Therefore, this study was conducted to understand the current state of safety practices based on the eight different themes. The findings from this study can be used to understand the status of safety practices and make use of the findings to improve the safety practices in the chemistry laboratories of Bhutan.

\section{METHOD}

\subsection{Sampling}

In this study, the target population was science students of class XI and XII, chemistry laboratory assistants, and the 
chemistry teachers of the three higher secondary schools of Samtse District. All three higher secondary schools of the District were selected. All the chemistry laboratory assistants, teachers teaching chemistry from classes IX to XII were included in the study. For the students' sample, simple random sampling was chosen to ensure the law of statistical regularity. Of the total 261 students; the confidence level considered was 95 percent and the confidence interval at 5 percent. The sample was calculated using the Cochran method of sample size determination. Therefore, the total sample size was 157 students. The student participants were randomly sampled. Since there were only three schools in the entire District, all 3 chemistry laboratory assistants and 9 chemistry teachers were involved in the study.

\subsection{Data Collection Tools}

In this study, three different questionnaires were developed using 5 points Likert Scale for the students, teachers, and laboratory assistants. The participants were required to rate the items/statement by ticking the most appropriate in their opinion.

A 41 items five point Likert scale survey questionnaire consisting of statements covering PPE, safety facilities, safety practices, skills \& knowledge, waste management and emergency planning. Further the students were interviewed with semi-structured questionnaires.

Similarly, a 49 items five point Likert scale survey questionnaire comprising aforementioned thematic areas were assessed. In addition, training and policy was also included. Further the teacher respondents were face to face interviewed and a checklist of safety items and procedures were provided. In the similar way, the laboratory assistants were also made to respond to the same survey questionnaire with additional thematic areas such as labeling and storage of chemicals and safety documents and policies availability.

\subsection{Data Collection}

The study is based on a mix method. The quantitative assessment was carried out using survey questionnaire with five point Likert scale and checklist and qualitative assessment was done through direct classroom observation and semi-structured interview. The survey inspection checklists were also used to collect information about the overall chemistry laboratory safety. The laboratory assistants filled the checklist personally. In addition, a semi-structured interview method had been used. For chemistry teachers and chemistry laboratory assistants, face to face interviews and for students, focus group discussions were conducted.

\subsection{Data Analysis Procedure}

The data collected from the qualitative and quantitative method were analysed separately. The data collected through qualitative methods like practical class observations and interviews were analysed thematically. The quantitative data collected using a questionnaire and checklist were analysed by using SPSS 22.0 (Statistical Package for Social Sciences). The inferential and descriptive analysis was done by running an independent sample t-test, calculating the mean, percentage, and standard deviation.

\subsection{Results Interpretation}

The results were categorized according to a mean interpretation scale adapted from past studies. The interpretive scale was used to benchmark respondents' rating towards schools' chemistry laboratory safety according to the mean score obtained. The ratings were divided into five levels: very poor, poor, moderate, good and very good. Further, Very good and good were categorised as positive, very poor and poor were categorised as negative, and moderate as moderate.

Table 1. Interpretation of Rating on Chemistry Laboratory Safety.

\section{Level of Rating Mean Range Interpretation}

\begin{tabular}{lll}
\hline $\begin{array}{l}\text { Strongly } \\
\text { Disagree }\end{array}$ & $1.00-1.80$ & Very Poor \\
Disagree & $1.81-2.60$ & Poor \\
Not Sure & $2.61-3.40$ & Moderate \\
Agree & $3.41-4.20$ & Good \\
Strongly Agree & $4.21-5.00$ & Very Good \\
\hline
\end{tabular}

Adapted from [27].

\subsection{Ethical Consideration}

The ethical issue in this study is taken into an account by the researchers. Before the data collection, the written permission to conduct the research was sought from the concerned authorities. Further, the consent was obtained from the participants who were interviewed.

\section{RESULTS \& DISCUSSION}

The findings are presented under eight major themes; PPE, safety facilities and equipment, general safety practices, safety knowledge and skills, EP, chemical storage and labeling, HWM, and training and policy. The interview 
verbatim are used and the anonymity of the interview participants are maintained using pseudonyms like T_01, T_ $02 \ldots$ for teachers, CLab_01, CLab_02... for laboratory assistants, Std_01, Std_02... for students and SFG_01, SFG_02... for students' focus group interview.

\subsection{Accidents and injuries}

The study through various means observed that there exist accident and injury incidences in the Chemistry laboratories in our schools. Of the 169 respondents 55 (32 percent) responded and agreed that they have been a part of an injury or accident incident in the lab. The cases were noted during the interview and checklist from the teachers and student participants as well. It was interesting to note that most of the incidents were due to poor handling of acid, glass apparatus and pipetting chemicals with the mouth. The observation was in fact close with what was observed by a similar study in Nepal where accidents were common and reasons being one of the major issues observed in the study [16].

It was also noted through the survey inspection checklist that none of the chemistry laboratories had maintained accidents records. The same was observed by some studies in Saudi university, where they also found no single laboratory that recorded the accidents and laboratory injuries [2]. The reason for the lack of accident records could be due to a lack of policy, awareness, and training.

\subsection{Personal Protective Equipment (PPE)}

The survey findings indicated varied responses among three different categories of participants regarding the use of PPE. The students marked "moderate" with average mean score of 3.32, teachers marked "good" with average mean score of 3.80 and laboratory assistants marked "very good" with average mean score of 4.60. This generally indicates school chemistry laboratories are doing quite well in terms of the proper use of PPE. However, students and teachers responded "poor" and "moderate" for the item "students always use hand gloves while handling chemicals" with mean scores of 2.50 and 2.89 respectively. The lack of such laboratory ethics could be because of the shortage of hand gloves as the checklist findings revealed that there were just 10 to 15 pairs of hand gloves in the chemistry laboratory for 30 to 43 students in each class. This finding is not in line with the laboratory safety guidelines. According to [31], suitable protective gloves should be worn while washing apparatus, handling dangerous chemicals, handling chemicals sensitive to the skin that can cause allergy, and handling hot apparatus. This finding was similar to the study conducted in Saudi Arabia where they found a lack of wearing hand gloves and the numbers of hand gloves were very less than the requirement [2]. It is also consistent with the study in Nepal where only 57 percent of the participants agreed that gloves were used while handling chemicals [16].

Secondly, students marked "poor" for the item "teachers wear safety goggles all the time during practical" with a mean score of 2.48. Further, this finding was supported by the findings from the checklist and class observation. The findings from the checklist have shown that in one of the schools there were only 3 safety goggles for 43 students. During the class observation too, most of the experiments were carried out without the use of safety goggles. This finding is not in agreement with the safety guidelines that say protective safety goggles must be worn in all circumstances and failure to do so will be regarded as negligence [31]. This finding is similar to the study by [18] at Pahang, Malaysia where his study found an inadequate amount of safety goggles in their school science laboratories.

The study findings also indicated enough laboratory coats for the students and teachers. On the other hand, some students were found wearing laboratory coats keeping the buttons untied and in two of the schools, the laboratory coats were short sleeves. Such laboratory coats with short sleeves and the habit of keeping buttons of lab coats untied may not fully protect the person from hazards such as a spill of chemicals. In the schools, teachers and laboratory assistants had a good practice of enforcing the students to wear PPE. Such practice is righteous and may have avoided many undesirable accidents.

\subsection{Safety Facilities and Equipment}

One of the causes of accidents in chemistry laboratories is due to inadequate facilities and equipment. Therefore, this study explored the availability of the following facilities: water, soap, glass disposal bins, safety manual, and proper ventilation, fume hood, and pipette filler. In the survey questionnaire, students and teachers marked "good" with mean scores of 3.95 and 4.14 respectively, whereas laboratory assistants marked "very good" with mean scores of 4.33. This finding indicates the availability of the safety facilities and equipment. Further, this finding was supported by checklist findings. Yet, unavailability of fume hood and pipette filler in all the schools was pronounced from the interview and checklist.

The findings have indicated the availability of soap and water. This helps in keeping laboratory workers safe from chemical contamination and poisoning. This finding is in line with [24], which states that even if hand gloves are worn, hands should be washed with soap and water immediately after working with any laboratory chemicals.

The use of glass apparatus is unavoidable in the chemistry laboratories, at the same time they are probable to break at 
any time. Therefore, the glass disposal bin is an important requirement for housekeeping. As required, study findings revealed the availability of glass disposal bins in all the chemistry laboratories. Interestingly, this finding is in contrast to the study in Saudi University and Virginia where their findings indicated the lack of glass disposal bins in their chemistry laboratory [29]. Such contrast findings could be the result of trained laboratory assistants in Bhutan because this study finding also indicated that all laboratory assistants of the schools were trained on laboratory safety management once.

However, this study also revealed the unavailability of fume hoods in the chemistry laboratories. This finding is in contrast to the findings in Sweden where they found that working and regularly inspected fume hoods are available in all the school laboratories [32]. Interestingly, teachers and laboratory assistants are aware of the significance of the fume hood. Thus, they strongly recommend fume hood for the chemistry laboratories. Some teachers pointed out that the new chemistry syllabus from classes XI-XII demands the use of fume hood because there are experiments which are supposed to be performed in a fume hood.

Likewise, this study finding revealed the unavailability of pipette filler in the chemistry laboratories. Such unavailability of pipette filler is not in agreement with the laboratory safety guidelines by [8] and [31] which discourages the students and teachers to pipette chemicals with mouth and encourages using pipette filler. Most teachers feel it is unsafe to pipette chemicals with the mouth. They also shared many incidences of student accidently sucking chemicals. Some students also shared the incidence where they mistakenly pipetted chemicals in their mouth.

\subsection{General Safety Practices (GSP)}

General safety practice in this study refers to common safe work practices followed in the chemistry laboratories as per the safety guidelines. In chemistry laboratories, the accidents and undesirable exposure to the hazardous chemical can be avoided to some extent by adhering to general safety practices. For this, in the survey, the students and teachers marked "very good" as shown in Table 2 and Table 3 respectively. This could mean that safety practices are followed properly in the chemistry laboratories. Further, this finding is supported by findings from the class observations and interview. It is interesting to note from the interview that teachers and lab assistants frequently brief students on safety rules and regulations. Most importantly, the safety rules and regulations were also found displayed on the walls of the chemistry laboratories. This finding is in agreement with [4] which state that it's imperative to create a culture of safety from the first meeting of the class. Similar to this finding, the study conducted in Sweden also depicted that all the teachers controlled the safety knowledge of the students before starting the laboratory work [32]. In contrast, the study conducted in Pahang, Malaysia found only 55.9 percent of the teachers explained science laboratory safety rules in the beginning of the school session.

Table 2. Students' rating on general safety practices in the chemistry laboratory.

\begin{tabular}{|c|c|c|c|}
\hline Items & Mean & SD & $\begin{array}{r}\text { Level of } \\
\text { Rating }\end{array}$ \\
\hline $\begin{array}{l}\text { Written safety rules and } \\
\text { regulations are explained in the } \\
\text { first practical class by the teacher. }\end{array}$ & 4.69 & 0.64 & $\begin{array}{l}\text { Very } \\
\text { Good }\end{array}$ \\
\hline $\begin{array}{l}\text { Practical classes are always } \\
\text { supervised by the teacher. }\end{array}$ & 4.71 & 0.67 & $\begin{array}{l}\text { Very } \\
\text { Good }\end{array}$ \\
\hline $\begin{array}{l}\text { A teacher does not allow you to } \\
\text { bring food and drinks to the } \\
\text { laboratory. }\end{array}$ & 4.53 & 0.87 & $\begin{array}{l}\text { Very } \\
\text { Good }\end{array}$ \\
\hline $\begin{array}{l}\text { Always clean the basin and other } \\
\text { equipment used before leaving the } \\
\text { laboratory. }\end{array}$ & 4.55 & 0.76 & $\begin{array}{l}\text { Very } \\
\text { Good }\end{array}$ \\
\hline $\begin{array}{l}\text { All girls come to the chemistry } \\
\text { laboratory with their hair tied at } \\
\text { their back. }\end{array}$ & 4.06 & 1.11 & Good \\
\hline Average & 4.50 & 0.53 & $\begin{array}{l}\text { Very } \\
\text { Good }\end{array}$ \\
\hline
\end{tabular}

Table 3. Teachers' rating on general safety practices in the chemistry laboratory.

\begin{tabular}{lccc}
\hline \multicolumn{1}{c}{ Items } & Mean & SD & $\begin{array}{c}\text { Level of } \\
\text { Rating }\end{array}$ \\
\hline $\begin{array}{l}\text { Written safety rules and } \\
\text { regulations are explained in the } \\
\text { first practical class by the teacher. }\end{array}$ & 4.33 & 1.0 & $\begin{array}{c}\text { Very } \\
\text { Good }\end{array}$ \\
$\begin{array}{llll}\text { I supervise all practical lessons. } & 4.67 & 0.71 & \begin{array}{c}\text { Very } \\
\text { Good }\end{array}\end{array}$
\end{tabular}


I do not allow students to bring

food and drinks in the laboratory.

4.67

0.71

Very

Good

Students always clean the basin and other equipment used before leaving the laboratory.

$4.0 \quad 1.32 \quad$ Good

All girls come to the chemistry laboratory with their hair tied at their back.

$\begin{array}{llll}\text { Average } & 4.45 & 0.82 & \text { Very } \\ \text { Good }\end{array}$

During the class observation, it was observed that teachers and laboratory assistants were actively supervising the students throughout the practical classes. This finding is in accordance with the guidelines of [4], which states that teachers have to closely supervise the students in chemistry laboratories all the times in order to minimize risk during the experiment [4].This finding is analogous to the study findings in junior secondary school laboratories in Gaborone where practical classes are well supervised by the teachers [23].

The findings from this study also indicated that food and drinks were strictly prohibited in the laboratory. This finding is congruent to the study findings in Nepal where they found the majority of the teachers were prohibiting food and beverages inside the laboratory [16], which is well aligned to the safety guidelines that emphasize not to allow students to eat or drink anything inside the chemistry laboratory ([4]; [8]; [31]).

\subsection{Safety Knowledge and Skills}

Table 4, 5, and 6 depicts that the overall safety knowledge and skills of the students, teachers and laboratory assistants' are above average. All the items in this category were marked "good" and above except the item on "I know how to use fire extinguisher" was marked "moderate" by the students and laboratory assistants. These findings on the use of fire extinguisher were further triangulated with the interview findings. Upon triangulation, it was found that 75 percent of the teachers were not confident to use fire extinguishers practically, except T_04 said he is confident to use fire extinguishers in case of emergency. Similarly, two laboratory assistants expressed unconfident to use fire extinguishers. Likewise, out of 20 student participants, only one student expressed his confidence to operate a fire extinguisher. As a result, this finding could mean that most of the students, teachers, and laboratory assistants are unable to use fire extinguishers. Actually, as per the guidelines of [4], the teachers who have the rights to use fire extinguishers in case of emergencies must be trained on its proper use.

Table. 4 Students response on safety knowledge and skills.

Items Mean SD $\begin{gathered}\text { Level of } \\ \text { Rating }\end{gathered}$

One should not face the mouth of

the test tube towards friends or self while heating substance in the $4.87 \quad 0.45$ Very Good test tube.

While mixing acid and water, the acid must be always added to $\quad 3.82 \quad 1.16 \quad$ Good water.

I know how to use first aid kit during an emergency

$\begin{array}{lll}3.54 & 0.85 \quad \text { Good }\end{array}$

I know how to use a fire extinguisher

$2.87 \quad 1.27$ Moderate

I know how to respond in case of a burn which occurs with contact $3.43 \quad 1.06$ Good to hot objects
Average
$3.70 \quad 0.62$ Good

Table 5. Teachers' response on safety knowledge and skills.

\begin{tabular}{|c|c|c|c|}
\hline Items & Mean & SD & $\begin{array}{l}\text { Level of } \\
\text { Rating }\end{array}$ \\
\hline $\begin{array}{l}\text { One should not face the mouth of } \\
\text { the test tube towards friends or self } \\
\text { while heating substance in the test } \\
\text { tube. }\end{array}$ & 4.67 & 0.71 & $\begin{array}{l}\text { Very } \\
\text { Good }\end{array}$ \\
\hline $\begin{array}{l}\text { While mixing acid and water, the } \\
\text { acid must be always added to } \\
\text { water. }\end{array}$ & 4.78 & 0.67 & $\begin{array}{l}\text { Very } \\
\text { Good }\end{array}$ \\
\hline $\begin{array}{l}\text { I can recognize the common } \\
\text { laboratory hazard symbols }\end{array}$ & 4.67 & 0.50 & $\begin{array}{l}\text { Very } \\
\text { Good }\end{array}$ \\
\hline $\begin{array}{l}\text { I know how to use first aid kit } \\
\text { during an emergency }\end{array}$ & 4.22 & 0.97 & $\begin{array}{l}\text { Very } \\
\text { Good }\end{array}$ \\
\hline
\end{tabular}


I know how to use a fire extinguisher

1.12

Very

Good

I know how to respond in case of a

burn which occurs with contact to $4.00 \quad 0.71 \quad$ Good hot objects

\begin{tabular}{|c|c|c|}
\hline Average & 4.33 & 0.37 \\
\hline
\end{tabular}

Table 6. Laboratory assistants' response on safety knowledge and skills.

Items Mean SD $\begin{gathered}\text { Level of } \\ \text { Rating }\end{gathered}$

One should not face the mouth of the

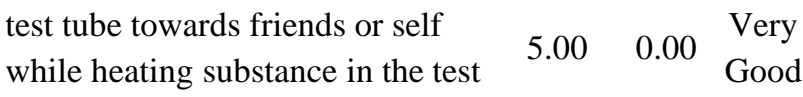
tube. $\begin{array}{llll}\text { While mixing acid and water, the } & 5.00 & 0.00 & \text { Very } \\ \text { acid must be always added to water. } & & & \text { Good }\end{array}$

I can recognize the common

laboratory hazard symbols

0.57 Very

Good

I know how to use first aid kit during an emergency

1.00 Good

I know how to use a fire extinguisher 3.00

1.00Moderate

I know how to respond in case of a burn which occurs with contact to hot objects

4.33

0.57 Very

I am aware of the negative health impact of mercury

$0.57 \begin{array}{ll}\text { Very } \\ \text { Good }\end{array}$

I can identify compatible and noncompatible chemicals

$4.00 \quad 0.00$ Good

I am aware of all my job

responsibilities as a laboratory

assistant

$\begin{array}{lll}5.00 & 0.00 & \text { Very } \\ \text { Good }\end{array}$

Average $\begin{array}{lll}4.33 & 0.37 & \text { Very } \\ & \text { Good }\end{array}$
$\mathrm{Su}$ and Hsu [as cited in [6]] explain that the accidents related to chemicals mostly occur due to the neglect of the precautionary symbols on the chemicals. Therefore, students and teachers should be able to recognize safety signs and symbols. For this, students' safety knowledge based on the recognition level of safety signs and symbols was investigated using null hypothesis: "class XI and XII students have the same level of recognizing safety signs and symbols". Students were asked to recognize and name eight common safety signs and symbols that were selected from class XI-XII practical manuals. The correct and incorrect answers from the test were computed and shown in Table 7. The data were analysed by giving one mark to the correct answer. No mark was given to the wrong, blank or more than two names for the hazard symbols.

Table 7 reveals that the majority of the students wrongly answered the symbols such as toxic, oxidizer, harmful and caution. This could mean that students' were not able to adequately recognize the common laboratory hazard symbols. However, it is interesting to note that the safety sign and symbols were displayed in all the chemistry laboratories. Moreover, all necessary safety signs and symbols were mentioned clearly in the practical manual for classes XI-XII. This finding is parallel to the finding from the study by [36], where they found that most of the students were not able to adequately recognize the common laboratory hazard symbols. This finding was also parallel to the study in Thailand, where the findings indicated that most students were unable to match chemicals with their safety signs correctly [6].

Table 7. T-test to conduct the effect of class on students' recognition level of common laboratory hazard symbols

\begin{tabular}{lllllll}
\hline Class & N & Mean & $\begin{array}{l}\text { Mean } \\
\text { difference }\end{array}$ & SD & P & Cohens d \\
\hline XI & 85 & 2.66 & & 2.191 & & \\
& & & 1.117 & & 00 & 0.62 \\
XII & 72 & 1.54 & & 1.310 & & \\
\hline
\end{tabular}

In this study, the significant difference of the students' ability to recognize common laboratory hazard symbols between class XI and XII were tested using independent sample t-test. The test revealed a statistically significant difference between the mean score of class XI $(\mathrm{M}=2.66)$ and class XII $(\mathrm{M}=1.54)$ at $\mathrm{p}=0.00, \alpha=0.05$. (Refer to Table 7). Since the $p$-value is less than alpha $(\alpha=0.05)$, the null hypothesis was rejected. The findings have shown that the class XI students $(\mathrm{M}=2.19)$ outdid class XII $(\mathrm{M}=1.31)$ students. Further, this is evident from Table 7 that 61.9 percent of class XI students could recognize the 
hazard symbol for oxidizer symbol as larger as 100 percent of the class XII students could not recognize the same symbol correctly. The similar result is also observed with respect to corrosive and irritant hazard symbols (Refer to Table 7). For this investigation, the sample size was above 30 participants, the effect size was calculated using the Cohens $d$ test. The value of 0.62 calculated from Cohens $d$ test confirms that the standardized measure of the effect size of the sample is above medium effect size. The better performance of class XI in recognizing safety signs and symbols could be due to the student's interest. The other reason could be because of the teacher's involvement in assuring the students to remember safety signs and symbols. As one of the teachers teaching class XI told that, he makes students remember safety signs and symbols thoroughly.

\subsection{Emergency Planning (EP)}

Emergency planning in this context is the process of accessing risk, creating plans for identified risk and implementing measures to avoid accidents. The students, teachers and laboratory assistants marked "good" and above for the emergency planning in terms of: availability of first aid kit, the readiness of wash bottles to be used as an eyewash, keeping walkways and exits free of obstruction, and awareness on the location of emergency exits and fire extinguishers. This finding is similar to study conducted in Swedish schools by [32]. Their findings have indicated that laboratory equipment such as safety showers, emergency first aid kits, and eyewash facilities were regularly checked. Hence, the finding of this study could mean that emergency planning based on the abovementioned aspects is at par with the chemistry laboratories of a developed country like Sweden. However, there are other aspects that need attention.

The finding from the checklist revealed that 100 percent of the chemistry laboratories were well equipped with the fire extinguisher. Further, the students and teachers were aware of the location of the fire extinguisher. However, one of the major issues observed in the study was that most of the teachers, laboratory assistants, and students were not confident to use fire extinguishers. Hence, the purpose of placing a fire extinguisher for the chemistry laboratory is defeated. This could be due to a lack of training on the usage of fire extinguishers and needs immediate attention.

Another, important requirement for the chemistry laboratory design is to have separate exit doors. However, $66.7 \%$ of the chemistry laboratories in the schools did not have separate emergency exit doors. This finding is in contrast to the study finding in junior secondary school laboratories in Gaborone where they found most of the laboratories with two exit doors in case of emergency [23].
In fact, the emergency exit doors are mandatory because of the large number of students it is very inconvenient to evacuate during mishaps. During the interview, most of the teachers and laboratory assistants expressed the need for a separate exit door.

Finally, the findings from the checklist indicated the absence of a separate written emergency action plan for the chemistry laboratories in all the schools. This finding is in contrast to the guidelines by [24] which emphasize every laboratory to have an emergency preparedness plan, in which details of the plan varies depending on the department and plans already in place. Further, Abbas

[1], claims that an emergency action plan is useful to cope with emergency situations. Nevertheless, most of the aspects of the emergency action plan are included in the Practical Manual for classes XI-XII. This could mean that in one way, there is emergency planning in school chemistry laboratories. However, separate documented emergency planning may have a greater impact.

\subsection{Chemical Storage and labelling}

Chemical storage in this study refers to the storage of chemicals in a separate chemical storeroom according to their hazard category, compatibility, and in alphabetical order. Labeling refers to the label of the chemicals based on the classification and legible labeling of hazardous chemicals. The additional items on chemical storage and labelling was included in the survey questionnaire for the lab assistants. For this, lab assistants marked "very good" with an overall mean score of 4.33. For the individual items, refer to Figure 1. Checklist findings too revealed the same. This finding is well aligned to [24] where they stated that incompatible material should be kept separate because the contact among these compatible chemicals results in serious explosion or the formation of substances that are highly toxic or flammable.

Table 8. The average mean score of response on hazardous waste management.

\begin{tabular}{llll}
\hline Participants & Mean & SD & Level of Ratings \\
\hline Students & 3.22 & 0.61 & Moderate \\
Teachers & 3.79 & 0.42 & Good \\
Laboratory & 4.42 & 0.58 & Very Good \\
Assistants & & &
\end{tabular}

The findings from this study also revealed that the chemicals are stored appropriately in the chemistry laboratories. This finding corresponds to the findings in Swedish schools where most of the teachers were satisfied with the chemical storage facilities [32]. This finding could mean that there is a good practice of storing chemicals, thereby reducing students and teachers' 
exposure to chemicals. According to [1], it states that the proper storage of chemicals can reduce occupational exposure to chemicals.

\subsection{Hazardous Waste Management (HWM)}

The survey findings indicated varied responses among three different categories of participants regarding the hazardous waste management as shown in Table 8. Hazardous waste management in this study refers to proper management of hazardous waste generated from the chemistry laboratory having potential threat to human health or the environment. Hazardous waste is any substance that causes harm to human health and to the environment if it is not adequately handled, treated, stored, transported, and disposed of [26].Therefore, hazardous waste management is imperative. The findings from the survey revealed the practice of proper hazardous waste management in terms of: diluting waste of acid and base with water before throwing into the sink, collecting organic waste in a separate container, and using the separate container for broken glass and sharp objects. These findings were further supported by the interview findings. However, most of the students, teachers and lab assistants agreed that acid and bases were not neutralized before throwing in the basin. Inline to this, one of the survey questionnaire items was also set to find how the chemicals waste such as salts, organic compounds, and acid and base are disposed of after the experiments. The item says "the chemicals used during practical are thrown directly into the drain/sink". The (64.3 percent) of the students, (33.3 percent) of the teachers, and (66.7 percent) of the laboratory assistants agreed that they throw the chemical waste directly into the sink.

This indicates that most hazardous chemical wastes were disposed into the sink without any treatment except diluting of acid with water, which finally flows to the environment. In contradiction to this finding [26] states that treatment of hazardous material before disposal is important in order to reduce concentrations of hazardous compounds. Further, [4] and [10] states that the chemical waste generated in the laboratory can result in serious damage to the environment. This disagreement could be due to lack of implementation of the code or maybe the amount of hazardous waste generated in the chemistry laboratory is considered negligible. However, there is a need to consider hazardous waste seriously in school chemistry laboratories.

\subsection{Training and Policy}

The findings from the survey data showed that 100 percent of the lab assistants have received at least one course on science laboratory management but no ( 0 percent) teachers received any training on science laboratory safety. This finding did not align with the guidelines by [4] which states that the teachers must receive all necessary training because in case of an emergency, teachers may have to act before medical personnel arrives. Similarly, [1] also states that training on chemical storage and handling are crucial to empower laboratory staff to be able to prevent potential accidents and to prepare them to respond in case of chemical accidents. Therefore, adequate safety training to the laboratory assistants and teachers is essential. It is interesting to note that, during an interview teachers and lab assistants expressed the need for training to make the chemistry laboratory a safer place. The teachers and lab assistants also marked "strongly agree" with mean scores of 4.67 and 5 respectively for the item: "My students and I would benefit from a short course or workshop on laboratory safety measures/practices." This finding is similar to findings in Nepal by [16], where the majority of the participants believed that they would benefit from the short course or workshop on laboratory safety. Similarly, the study in West Virginia high schools has found that teachers were in favour of the safety training of all science teachers regardless of discipline [29].

The overall safety practices in the chemistry laboratories depend on certain safety guidelines, policies and its implementation. Regarding the safety policy, there were varied opinions as laboratory assistants marked "strongly agree" for the item on "there is safety policy for the chemistry laboratory in schools" whereas, teachers marked "not sure". To elucidate mixed findings, the researcher further investigated by asking the documents. It was found that safety guidelines in the practical manual were available but policy was not. This finding is in contrast to the findings in West Virginia where they found a lack of safety manual [29]. However, this study finding indicated no evidence of a separate policy document for chemistry laboratory safety. This finding on the lack of policy for chemistry laboratory safety is consistent with [16] where they stated that some developing countries lack policy for chemical safety.

\section{RECOMMENDATIONS}

Based on the findings of this study, in order to enhance safety practices and facilities in the chemistry laboratories to avoid unbearable loss due to accidents. The study recommends MoE in consultation with REC may provide training on chemistry laboratory safety to chemistry teachers and the lab assistants. Teachers and lab assistants need to create awareness on the importance of laboratory safety signs and symbols and should come up with innovative pedagogical techniques to ensure that each student recognizes safety signs and symbols correctly. 
Further, Lab assistants have to keep records of accidents and injuries in the chemistry laboratories. School management should ensure the availability of PPE and equipment such as hand gloves, safety goggles, pipette filler, and fume hood for the chemistry laboratory. Finally, MoE in collaboration with NEC and REC may come up with treatment strategies for hazardous chemical waste from the school chemistry laboratories to avoid environmental pollution.

\section{COMPETING INTERESTS}

Authors have declared that no competing interests exist.

\section{REFERENCES}

[1] Abbas, M. (2016). Chemical safety in academic laboratories: An exploratory factor analysis of safe work practices \& facilities in a university. Journal of Safety Studies, II(1), 114. doi:10.5296/jss.v2i1.8962

[2] Abbas, M., Zakaria, A. M., \& Balkhyour, M. A. (2016). Investigation of safety facilities and safe practices in chemical laboratories of a Saudi university. Journal of Environment and Safety, 7(2), 141-147. doi:daikankyo.E15 RP1001

[3] AcarSesena, B., \& Mutlub, A. (2014). An action research to overcome undergraduates' laboratory anxiety. Procedia Social and Behavioral Sciences, 546-550. doi:10.1016/j.sbspro.2014.09.241

[4] American Chemical Society. (2016). American chemical society guidelines for chemical safety in secondary schools. Washington: Author.

[5] Anilan, B. (2010). The recognition level of the students of science education about the hazard symbols of chemicals. Procedia Social and Behavioral Sciences, 4092-4097. doi:10.1016/j.sbspro.2010.03.646

[6] Anza, M., \& Kuma, B. (2016). Investigation of laboratory and chemical safety in Wolaita Sodo University, Ethiopia. Chemistry and Materials Research, VIII, 23-33.

[7] Artdej, R. (2012). Investigating undergraduate students' scientific understanding of laboratory safety. ProcediaSocial and Behavioral Sciences, 46, 5058-5062. doi:10.1016/j.sbspro.2012.06.385

[8] Curriculum and Professional Support Division. (2004). Science laboratory management. (N. Giri, Ed.) Paro: Author.

[9] Ezrailson, C. (2013). Danger in the school science lab: Are students at risk? Proceedings of the South Dakota Academy of Science, 149-162.

[10] Finster, D. C. (Ed.). (2017). Safety in academic chemistry laboratories (8th ed.). Washington: American Chemical Society.

[11] Gibson, J. H., Schroder, I., \& Wayne, N. L. (2014). A research university's rapid response to a fatal chemistry accident: Safety changes and outcomes. Journal of Chemical Health \& Safety, 18-26. doi:10.1016/j.jchas.2014.01.003
[12] Hasari, A. İ. (2019). Acute inhalation injury. The Eurasian The Journal of Medicine, 28-35. doi:10.5152/eajm.2010.09

[13] Hill, R. H., \& Finster, D. C. (2010). Laboratory safety for chemistry students. Canada: A John Wiley \& Sons, Inc.

[14] Ho, C.-C., \& Chen, M.-S. (2017). Risk assessment and quality improvement of liquid waste management. Waste Management, 578-586. doi:10.1016/j.wasman.2017.09.029

[15] Hofstein, A., \& Mamlok-Naaman, R. (2007). The laboratory in science education. Chemistry Education Research and Practise, 105-107.

[16] Kandel, K. P., Neupane, B. B., \& Giri, B. (2017). Status of chemistry lab safety in Nepal. PLoS ONE, 1-10. doi:10.1371/journal.pone.0179104

[17] Langerman, N. (2009). Laboratory safety. Journal of Chemical Health \& Safety, 40-50. doi:10.1016/j.jchas.2009.03.004

[18] Makmal, P. K. (2018). Assessing awareness on laboratory safety: A case study in Pahang, Malaysia. Journal Pendidikan Malaysia, 73-80. doi:10.17576/JPEN-201843.02-07

[19] Marendaz, J.L., Suard, J.C., \& Meyer, T. (2012). A systematic tool for assessment and classification of hazards in laboratories (ACHiL). Safety Science, 168-176. doi:10.1016/j.ssci.2012.10.001

[20] Martin, S., \& Griswold, W. (2009). Human health effects of heavy metals. Environmental Science and Technology Briefs for Citizens, 1-6.

[21] Ministry of Education. (2014). Bhutan education blueprint 2014-2014 (1st ed.). Thimphu, Bhutan: Author.

[22] Ministry of Education. (2018). Annual education statistics 2018. Thimphu: Ministry of Education.

[23] Mogopodi, D., Paphane, B., \& Petros, S. (2015). Assessment of chemical management practices and safety in junior secondary school laboratories in Gaborone. Journal of Chemical Health \& Safety, 1-11. doi:10.1016/j.jchas.2015.01.001

[24] Moran, L., \& Masciangioli, T. (Eds.). (2010). Chemical laboratory safety and security. Washington: National Academy of Sciences.

[25] Nascimento, E. S., \& Filho, A. T. (2010). Chemical waste risk reduction and environmental impact generated by laboratory activities in research and teaching institutions. Brazilian Journal of Pharmaceutical Sciences, 46(2), 187198.

[26] National Environment Commission (2002). Environmental codes of practice for hazardous waste management. Thimphu: Author.

[27] Orlanda-Ventayen, C. C., \& Ventayen, R. J. (2017). Role of social media education: A teachers' perspective. ASEAN Journal of Open Distance Learning, 1-7.

[28] Parliament of Bhutan. (2009). Waste Prevention and Management Act 2009. Thimphu: Author.

[29] Richards-Babb, M., Bishoff, J., Carver, J. S., Fisher, K., \& Robertson-Honeker, J. (2010). Keeping it safe: Chemical safety in the high school laboratory. Journal of Chemical Health and Safety, 6-14. doi:10.1016/j.jchas.2009.05.001

[30] Royal Education Council (2012). Science curriculum framework PP-XII. Paro: Author. 
[31] Royal Education Council. (2016). Chemistry practical works manual for classes XI and XII. Paro: Author.

[32] Schenk, L., Taher, I. A., \& Oberg, M. (2018). Identifying the scope of safety issues and challenges to safety management in Swedish middle school and high school chemistry education. Journal of Chemical Education, 1-8. doi:10.1021/acs.jchemed.8b00054

[33] Sethy, S. K., \& Ghosh, S. (2013). Effect of heavy metals on germination of seeds. Journal of Natural Science, Biology and Medicine, 4(2), 272-275. doi:10.4103/09769668.116964

[34] Tchounwou, P. B., Yedjou, C. G., Patlolla, A. K., \& Sutton, D. J. (2012). Heavy metal toxicity and the environment. Molecular, Clinical and Environmental Toxicology, 133163.

[35] Tsuji, Y., Tonakura, K., \& Hayashi, R. (2016). Chemical substance management system at the University of Tokyo. Journal of Environment and Safety, 7(2), 129-131. doi:daikankyo.E15PROCP27

[36] Wangdi, D., \& Tshomo, S. (2016). Investigating chemical laboratory safety based on students' ability to recognise the common laboratory hazard symbols. (D. Thinley, S. Rinchen, \& C. Leach, Eds.) Educational Innovation and Practice, 01(01), 